\title{
O FARMACÊUTICO NA PROMOÇÃO DA SAÚDE: POSSIBILIDADES PARA A RESOLUBILIDADE DO SUS?
}

\author{
Annyelly Antônia Braga de Lima'; Tatiane de Oliveira Silva Alencar² \\ 1. Bolsista PIBIC/CNPq, Graduando em Farmácia, Universidade Estadual de Feira de Santana, \\ e-mail:anybraga@gmail.com \\ 2. Orientador, Departamento de Saúde, Universidade Estadual de Feira de Santana, \\ e-mail: tatifarmauefs@yahoo.com.br
}

PALAVRAS-CHAVE: Resolubilidade, Promoção da Saúde; Assistência Farmacêutica.

\section{INTRODUÇÃO}

A universalização do sistema de saúde teve como marco histórico a $8^{\circ}$ Conferência Nacional de Saúde, desde então a promoção da saúde vem sendo discutida. A promoção da saúde é uma estratégia de articulação transversal, que coloca em foco todos os fatores que colocam em risco à saúde da população, visando a implantação de mecanismos que minimizem as situações de vulnerabilidade (BRASIL, 2015). Desta forma, a promoção da saúde parte de uma concepção ampla do conceito de saúde e de seus determinantes. No entanto é necessário uma articulação gerencial e técnico cientifico com uma equipe multiprofissional que seja corresponsável no processo de saúde.

Após a aprovação em 1998 da Política Nacional de Medicamentos (PNM), a assistência farmacêutica passa a ser entendida como parte integrante de um conjunto de práticas voltadas para a promoção, prevenção e recuperação de saúde, contemplando atividades que extrapolam o simples abastecimento de medicamentos. Desta forma, segundo Marin e colaboradores (2003) os municípios passam a assumir uma "série de responsabilidades que exigem mobilização de conhecimento e habilidades técnicas, gerenciais e políticas em relação à assistência farmacêutica."

Para Oliveira, Assis e Barboni (2007) a reorientação da AF trazida na PNM, direcionada principalmente para a descentralização da gestão e melhor cobertura das necessidades locais de saúde, de acordo com critérios epidemiológicos, trouxe consigo a necessidade de ampliação das atividades da AF dentro do sistema de saúde público. Assim, além das atividades relacionadas com o abastecimento de medicamentos (programação, seleção, aquisição, controle de qualidade e distribuição), passou a incorporar atividades relacionadas ao acompanhamento e avaliação da utilização pelo usuário; à obtenção e a difusão de informações e à educação permanente de profissionais de saúde, de usuários e da comunidade para assegurar o uso racional de medicamentos e a promoção da saúde, desta forma, tornando o processo de saúde resolutivo. A resolubilidade pode ser entendida como a resposta adequada às demandas, de acordo com as necessidades individuais e coletivas, em todos os níveis da atenção, constituindo-se resultado da confluência das demais dimensões: acesso, acolhimento, vínculo e responsabilização (SANTOS, ASSIS, 2006).

Partindo dessa premissa, uma assistência farmacêutica resolutiva na atenção básica deve permitir que o usuário obtenha o medicamento apropriado para sua situação clínica, nas doses e período de duração do tratamento que satisfaçam suas necessidades individuais, acompanhado das informações adequadas para o uso resultando em uma qualidade de vida para o usuário. Logo, todas as etapas do ciclo da assistência farmacêutica são importantes para que esta contribua para a resolubilidade do serviço de saúde, se uma etapa apresenta alguma falha, as consequências serão em cascata para todas as outras etapas subsequentes e ao final o grande prejudicado será o usuário de medicamentos. Assim fazemos o seguinte questionamento: quais as concepções dos farmacêuticos da rede municipal de saúde de Feira de Santana-Ba sobre 
promoção da saúde? E como os farmacêuticos contribuem para a resolubilidade do SUS a partir da promoção da saúde?

O trabalho tem como objetivo geral analisar a contribuição do farmacêutico na rede municipal de saúde de Feira de Santana-BA para a promoção da saúde e resolubilidade do SUS. Como objetivos específicos tem-se: identificar o perfil dos farmacêuticos; caracterizar os serviços farmacêuticos oferecidos aos usuários; identificar as concepções dos farmacêuticos sobre promoção da saúde.

\section{METODOLOGIA}

Estudo qualitativo fundamentado nas relações, opiniões e interpretações humanas, permite desvelar processos sociais, construir novas abordagens, revisar e criar novos conceitos e categorias (MINAYO, 2010). Como sujeitos da pesquisa, previu-se a participação de farmacêuticos que trabalham nas farmácias municipais do SUS de Feira de Santana-BA. Para a produção dos dados, seriam empregadas a entrevista semiestruturada e a observação sistemática (TRIVIÑOS,1998), os quais seriam analisados utilizando-se a técnica de análise de conteúdo. Os aspectos éticos previstos na Resolução n 466/2012 foram obedecidos.

\section{RESULTADOS E DISCUSSÃO}

Os resultados aqui destacados referem-se às contribuições obtidas a partir da revisão de literatura, particularmente nos estudos (ALENCAR; NASCIMENTO, 2012; MACHADO et al., 2012; MORAES, 2012; ALENCAR, 2013) já produzidos no município de Feira de Santana. Isso porque não foi possível fazer a coleta de dados propriamente dita a partir das entrevistas com farmacêuticos das farmácias públicas, conforme previsto no plano de trabalho.

A análise de tais estudos permitiram organizar dois aspectos para análise: serviços farmacêuticos oferecidos aos usuários nas farmácias públicas do SUS; e Assistência farmacêutica: que promoção da saúde?

Serviços farmacêuticos oferecidos aos usuários nas farmácias públicas do SUS: Os serviços farmacêuticos podem ser entendidos como atividades desenvolvidas nas farmácias por farmacêuticos. Conforme disposto na Resolução CFF nº 499/2008 (CFF, 2008), compreende: elaboração do perfil farmacoterapêutico, avaliação e acompanhamento da terapêutica farmacológica de usuários de medicamentos, determinação quantitativa do teor sanguíneo de glicose, verificação de pressão arterial e temperatura corporal, aplicação de medicamentos injetáveis, execução de procedimentos de inalação e nebulização, realização de curativos de pequeno porte, colocação de brinco e participação em campanhas de saúde.

Esses serviços podem ser realizados em farmácias públicas ou privadas, mas sabe-se que nem todos eles precisam ser realizados nas farmácias públicas, já que, em geral, estão integradas ao serviço de saúde onde muitos serviços são realizados. Isso porém, não exclui a possibilidade de que sejam realizados nas farmácias. Por outro lado, sabe-se também que as farmácias públicas não dispõem de condições propícias para o desenvolvimento dos serviços, conforme evidenciam estudos ao revelarem a desestruturação da assistência farmacêutica no SUS (ALENCAR; NASCIMENTO, 2012).

No geral, há apenas a dispensação de medicamentos, momento no qual são disponibilizadas orientações a respeito da utilização dos mesmos. Ressalte-se que, a dispensação também não ocorre conforme previsto nas disposições legais já que, na maioria das vezes, não é realizada por farmacêutico, mas sim por técnicos de enfermagem ou outro profissional de saúde do serviço. A exceção corresponde àqueles programas e medicamentos que seguem protocolos especiais estabelecidos pelo Ministério da Saúde, que exigem a dispensação pelo farmacêutico, a exemplo do Programa de Hepatites, Programa de Controle da Hanseníase, Programa de Controle das DST/AIDS e Programa de Controle da Tuberculose. 
Não se identificou estudos locais a respeito dos serviços farmacêuticos no Programa Farmácia Popular do Brasil (PFPB), mas outros estudos (SILVA; CAETANO, 2015) apontam que, a despeito de ampliar o acesso aos medicamentos, o programa não oferece maiores benefícios aos usuários no que tange aos serviços farmacêuticos, ainda que tenha uma estrutura e equipe diferenciada em relação aos outros serviços de saúde no SUS.

Assistência farmacêutica: que promoção da saúde?

A Assistência farmacêutica é definida como um conjunto de ações voltadas à promoção, proteção e recuperação da saúde, tanto individual como coletiva, tendo o medicamento como insumo essencial e visando o acesso e seu uso racional. Este conjunto de ações envolve a pesquisa, o desenvolvimento e a produção de medicamentos e insumos, bem como a sua seleção, programação, aquisição, distribuição, dispensação, garantia da qualidade dos produtos e serviços, acompanhamento e avaliação de sua utilização, na perspectiva da obtenção de resultados concretos e da melhoria da qualidade de vida da população (BRASIL, 2004a).

Observa-se que a promoção da saúde está prevista no conjunto de ações que integram a assistência farmacêutica. Contudo, não se constata que essa é uma prática no cotidiano dos farmacêuticos, que está muito mais voltada para a recuperação da saúde, até mesmo entre os farmacêuticos que integram o Núcleo de Apoio à Saúde da Família - NASF (ALENCAR, 2013), que deveria centrar-se em atividades de promoção da saúde, especialmente àquelas relativas à promoção do uso racional de medicamentos e qualificação das atividades de assistência farmacêutica. Esta é, portanto, uma lacuna importante a ser resolvida nas ações que integram o trabalho farmacêutico no SUS (VIEIRA, 2007).

\section{CONSIDERAÇÕES FINAIS}

Há indicativos de que as atividades profissionais do farmacêutico nas farmácias públicas estão centradas na disponibilidade e dispensação de medicamentos, não sendo oferecidos serviços farmacêuticos previstos nas disposições legais relativas à atuação dos farmacêuticos. Portanto, há predominância das ações relacionadas à cura e prevenção, mas não se identifica ações voltadas à promoção da saúde de maneira significativa. Isso evidencia o quão longe as farmácias públicas estão de serem consideradas estabelecimentos de saúde, haja vista que a forma como se processam as relações entre o farmacêutico e o usuário do medicamento não tem oportunizado a educação em saúde.

\section{REFERENCIAS}

ALENCAR, T. de O. Silva; NASCIMENTO, M. A. A. Assistência Farmacêutica no Programa Saúde da Família: encontros e desencontros do processo de organização. Ciência e Saúde Coletiva (Impresso), v. 16, p. 3939-3949, 2011.

BRASIL. Ministério da Saúde. Conselho Nacional de Saúde. Resolução no 338, de 06 de maio de 2004. Aprova a Política Nacional de Assistência Farmacêutica. Brasília, DF: Conselho Nacional de Saúde, 2004. Disponível em: <http://portal.saude.gov.br〉. Acesso em: 20 mar. 2010.

BRASIL. Resolução/CONEP no 466 de 12 de dezembro de 2002. Dispõe sobre diretrizes e normas regulamentadoras de pesquisas envolvendo seres humanos. Ministério da Saúde, 2012.

BRASIL. Ministério da Saúde. Secretaria de Vigilância em Saúde. Secretaria de Atenção à Saúde. Política Nacional de Proteção à Saúde. Brasília: Ministério da Saúde, 2015. 
Machado, C. S.; ALENCAR, T. de O. S. ; COSTA, S. C. C. ; ALENCAR, B. R. . Descarte de medicamentos: uma análise da prática no Programa Saúde da Família. Ciência e Saúde Coletiva (Impresso), v. 19, p. 2157-2166, 2014.

MARIN, Nelly (org.) et al. Assistência Farmacêutica para Gestores Municipais de Saúde. Rio de Janeiro: OPAS/OMS, 2003, 336 p.

MINAYO, M. C. de S. O desafio do conhecimento: Pesquisa qualitativa em saúde. 12. ed. São Paulo: Hucitec/Abrasco, 2010.

OLIVEIRA, L. H.; MATTOS, R. A.; SOUZA, A. I. S. Cidadãos Peregrinos: os "usuários" dos SUS e os significados de sua demanda a prontos-socorros e hospitais no contexto de um processo de reorientação do modelo assistencial. Ciênc. Saúde Coletiva, v. 14 n.05, Rio de Janeiro, nov. 2009

SANTOS, A. M.; ASSIS, M. M. A. Da fragmentação à integralidade: construindo e (des)construindo a prática de saúde bucal no Programa de Saúde da Família (PSF) de Alagoinhas, BA. Ciência e saúde coletiva, Rio de Janeiro, v. 11, n. 1, p.53-61, 2006.

TRIVIÑOS, Augusto Nivalbo Silva. Introdução à pesquisa em ciências sociais: a pesquisa qualitativa em educação. São Paulo: Atlas, 1998.

VIEIRA, F. S. Possibilidades de contribuição do farmacêutico para a promoção da saúde. Ciênc. saúde coletiva, v. 12, n. 1, p.213-220, jan./mar. 2007. 